\title{
Clinical practice guidance for hepatology and liver transplant providers during the COVID-19 pandemic: APASL expert panel consensus recommendations
}

\author{
APASL Covid-19 Task Force · George Lau ${ }^{1,2} \cdot$ Manoj Sharma ${ }^{3}$
}

Received: 8 May 2020 / Accepted: 9 May 2020 / Published online: 23 May 2020

(c) Asian Pacific Association for the Study of the Liver 2020

\begin{abstract}
Background Confronting a once-in-a-century pandemic with COVID-19, tremendous stress has been placed in all walks of life worldwide.

Aims In order to enhance scientific information interflow in the arena of liver diseases in Asia-Pacific region during this difficult time, Asian-Pacific Association for the Study of the Liver (APASL) has taken the initiative to form the APASL COVID-19 Taskforce to formulate a clinical practice guidance in Hepatology, liver-related oncology, transplantation and conduct of clinical trials.

Methods A taskforce with 22 key opinion leaders in Hepatology from 16 countries or administration regions in Asia-Pacific regions was formed and through intense interaction via webinar, this guidance was formulated. Based on scientific data and experiences, recommendations were made in the management of liver injury, liver transplantation, autoimmune diseases, chronic liver diseases, delivery of elective and emergency services and conduct of clinical trials.

Conclusions This is the first consensus clinical guidance synthesized by APASL for our hepatologist and their allied medical personal.
\end{abstract}

Keywords COVID-19 · APASL · Guidance · Liver injury · ACLF · LDLT · DDLT · Immunosuppression · CLD · Hepatology

\section{Introduction: [Payawal Diana (Philippines), Tanwandee Tawesak (Thailand)]}

As per World Health Organisation (WHO) on 4 May 2020, COVID-19 has been responsible for 3,407,747 confirmed cases with $238,198(7.0 \%)$ deaths around the world [1].

The members of APASL COVID 19 Task force are listed in acknowledgements.

George Lau

gkklau@hnhmgl.com; gkklau@netvigator.com

Manoj Sharma

manojkumardm@gmail.com

1 Humanity \& Health Medical Group, Hong Kong, SAR, China

2 The Fifth Medical Center of Chinese, PLA General Hospital, Beijing 100039, China

3 Department of Hepatology, Institute of Liver and Biliary Sciences, New Delhi, India
There is an urgent need for guidance in the practice of Hepatology. A taskforce with 22 members from 16 countries or administration regions in Asia-Pacific regions was formed and through intense interaction via webinar, this guidance was made. Our Taskforce has also formed the electronic database to collect liver injury data from patients who suffered from COVID-19 in Asia-Pacific region "APCOLIS" study ("APASL COVID Liver Injury Spectrum) (https:// www.surveymonkey.com/r/covid-liver). These recommendations suggest preferred approaches to the diagnostic, therapeutic, and preventive aspects of care. They are intended to be flexible and modifiable according to local conditions. To more fully characterize the quality of evidence supporting the recommendations, the Guideline Committee of the APASL adopted a Class (reflecting benefit versus risk) and Level (assessing strength or certainty) of Evidence reported with each recommendation [2]. 


\section{Overview: [Sharma Manoj (India), Wasim Jafri (Pakistan), Merican Ismail (Malaysia)]}

\section{Epidemiology, clinical features and assessment}

WHO recommends using various categories (no cases, sporadic cases, clusters of cases and community transmission) to describe transmission patterns at national and subnational levels (wherever possible) to guide decisions for preparedness, readiness and response activities. According to current evidence, COVID-19 virus is primarily transmitted between people through respiratory droplet, by direct contact with infected people or contact with contaminated surfaces in the immediate environment or with objects used on the infected person. Airborne transmission may be possible when procedures that generate aerosols are performed on infected patients. Such procedures include endotracheal intubation, bronchoscopy, open suctioning, administration of nebulized treatment, manual ventilation, turning the patient to the prone position, disconnecting the patient from the ventilator, non-invasive positive-pressure ventilation, tracheostomy, and cardiopulmonary resuscitation. In addition, several studies reported that SARS$\mathrm{CoV}-2$, were isolated from feces and urine patients [1]. But it is unclear whether human-to-human transmission can be implemented by the above routes. Asymptomatic patients can also be a source of infection [3]. Early dynamics studies in Wuhan suggested a doubling time of the number of infected persons of 6-7 days and a median $\mathrm{R}_{0}$ value of 5.7 (95\% CI 3.8-8.9) [4].

In a meta-analysis of 43 studies involving 3600 COVID19 patients, fever [83.3\% (95\% CI 78.4-87.7)], cough [60.3\% (54.2-66.3)], and fatigue [38.0\% (29.8-46.5)] were the most common clinical symptoms, followed by increased sputum production, shortness of breath, and myalgia, with estimated prevalence just under $30 \%$ for each, respectively [5]. Of 1141 confirmed COVID-19 cases from Wuhan, 183 (16\%) presented with gastrointestinal symptoms only [6]. The most common laboratory abnormalities were elevated C-reactive protein [68.6\% (58.2-78.2)], decreased lymphocyte count [57.4\% (44.8-69.5)] and increased lactate dehydrogenase [51.6\% (31.4-71.6)]. Ground-glass opacities [80.0\% (67.3-90.4)] and bilateral pneumonia $[73.2 \%(63.4-82.1)]$ were the most frequently reported findings on computed tomography. The overall estimated proportion of severe cases and case-fatality rate was $25.6 \%(17.4-34.9)$ and $3.6 \%$ (1.1-7.2), respectively [5]. According to the US Centre for Disease Control and Prevention (CDC), patients $>65$ years old, with cardiovascular disease, diabetes mellitus, morbid obesity, chronic obstructive pulmonary disease, or chronic liver disease are at higher risk for severe COVID-19. ${ }^{7}$
More prominent laboratory abnormalities (lymphopenia, elevated D-dimer, LDH) may be risk factors for poor outcome [8]. Recently, risk score model such as CALL (Comorbidities, older Age, higher Lactate dehydrogenase and lower Lymphocyte count) had been shown to have positive and negative predictive values of disease progression of $50.7 \%(38.9 \%-62.4 \%)$ and $98.5 \%(94.7 \%-99.8 \%)$, respectively [9].

WHO case definition includes (1) suspect case-a patient with acute respiratory illness (fever and at least one sign/ symptom of respiratory disease, e.g., cough, shortness of breath), and a history of travel to or residence in a location reporting community transmission of COVID-19 disease during the 14 days prior to symptom onset; or patient with any acute respiratory illness and having been in contact with a confirmed or probable COVID-19 case in the last 14 days prior to symptom onset; or a patient with severe acute respiratory illness and the absence of an alternative diagnosis that fully explains the clinical presentation; (2) probable case-a suspect case for whom testing for the COVID-19 virus is inconclusive, or a suspect case for whom testing could not be performed for any reason; (3) confirmed case -a person with laboratory confirmation of COVID-19 infection, irrespective of clinical signs and symptoms [1]. Countries may need to adapt case definitions depending on their local epidemiological situation and other factors. Confirmation of COVID-19 is based on detection of virus RNA by nucleic acid amplification test (NAAT) such as real-time reversetranscription polymerase chain reaction (rRT-PCR). The viral genes targeted so far include the N, E, S and RdRP genes. RNA extraction should be done in a biosafety cabinet in a BSL-2 or equivalent facility.

\section{Recommendations}

(1) COVID-19 patients should be diagnosed based on World Health Organization interim guidance. [Class I, level C]

(2) Decision of virological testing should be based on clinical and epidemiological factors and linked to an assessment of the likelihood of infection. [Class I, level C]

\section{How to assess and manage liver injury in Covid-19 patients? [Lau George (Hong Kong SAR and Beijing, China), Sharma Manoj (India), Hasmik Ghazinyan (Armenia), Guan Richard (Singapore)]}

The pattern of liver injury is mainly hepatocellular, rather than cholestatic, with elevation of serum alanine transaminases. Most studies have taken any elevation of liver enzymes as evidence of liver injury [10-12]. In one study, a differentiation 
was made between elevated liver enzymes (any elevation above the ULN) and liver injury (ALT and/or AST $>3 \times \mathrm{ULN}$; ALP, GGT, and/or total bilirubin $>2 \times \mathrm{ULN}$ ). Elevated liver enzymes and liver injury were seen in 50\% and 5\% at admission; and $76.3 \%$ and $21.3 \%$ during hospitalization respectively [12]. Rarely, COVID-19 infection can present as acute hepatitis with transaminases 10-20x ULN at admission with all other causes having been ruled out [13].

The underlying mechanism of liver injury remains speculative. The putative mechanisms of liver injury in COVID19 infection include direct cytopathic effects of the virus, immune imbalance and cytokine storm related multiorgan damage, hypoxia-reperfusion dysfunction and drug induced liver injury due to various types of drugs used for management of COVID-19 infection.

\section{Direct cytopathic effects of the virus}

One recent study using single cell RNA sequencing on fresh liver tissue specimens from 4 deceased donors of liver transplants (after circulatory death) found ACE 2 expression in $59.7 \%$ of cholangiocytes cluster of cells as compared to $2.6 \%$ of hepatocytes. Average expression level in hepatocytes is twentyfold less than the expression level in the cholangiocytes population. In fact ACE expression level in cholangiocytes is comparable to Alveolar Type 2 cells [14]. Studies in liver ductal organoids inoculated with COVID-19 found that human liver ductal organoids are susceptible to COVID- 19 infection and support robust viral replication, and COVID19 infection impairs the barrier and bile acid transporting functions of cholangiocytes [15]. In a mouse model of acute liver injury with partial hepatectomy, ACE2 expression in the liver was down regulated on the first day, but it was elevated up to twice of the normal level on the third day and returned to normal level on seventh day when the liver recovered and hepatocyte proliferation stopped. The experimental results implied the up regulation of ACE2 expression in the liver was caused by compensatory proliferation of hepatocytes derived from bile duct epithelial cells during acute liver injury [16]. Considering the COVID-19 patients with liver injury mainly manifests as elevation of serum aminotransferases ( cholestatic enzymes are elevated less commonly), it seems that hepatocytes are not targeted by COVID-19,or at least not through ACE2. Liver damages in patients might not be caused directly by viral infection of hepatocytes and liver injury in COVID-19 may thus have alternative pathophysiology and etiology.

\section{Immune imbalance and cytokine storm related multiorgan damage}

Pathologically, liver injury is accompanied by hepatocyte degeneration, focal necrosis, capillary bile duct cholestasis and inflammation in the portal area but interestingly, SARSCoV2 cannot be detected [17]. In the absence of influenza virus particles in the liver, "collateral damage" resulting from expanding $\mathrm{CD}^{+} \mathrm{T}$-cell populations has been implicated in the pathogenesis of liver injury during influenza infections [18] In keeping with this, post-mortem liver biopsy in patients who died from COVID-19 showed only microvesicular steatosis, accompanied by hyperactivation of $\mathrm{T}$ cells suggesting that liver injury is likely immune mediated rather than direct cytopathic damage as described in other viral respiratory disease [19]. The overproduction of proinflammatory cytokines (tumour necrosis factor,IL-6, (IL)-2, IL-7, interferon- $\gamma$ inducible protein 10 , monocyte chemo attractant protein 1 , macrophage inflammatory protein $1-\alpha$ and IL-11) have been described as a cytokine storm, leading to an increased risk of vascular hyperpermeability, multiorgan failure, and eventually death when the high cytokine concentrations are unabated over time [20]. Activation of coagulation pathways during the immune response to infection results in over production of pro inflammatory cytokines leading to multiorgan injury. During inflammation, the anticoagulant concentrations declined due to reduced production and increasing consumption. This procoagulat-anticoagulant imbalance predisposes to the development of microthrombosis, disseminated intravascular coagulation and multiorgan failure [21].

\section{Hypoxia reperfusion dysfunction}

Hypoxia and shock induced by COVID-19-related complications (such as respiratory distress syndrome, systemic inflammatory response syndrome, and multiple organ failure) may also cause hepatic ischemia and hypoxia reperfusion dysfunction. Oxygen reduction and lipid accumulation in hepatocytes during shock and hypoxic conditions could lead to cell death. The subsequent mitochondrial damage, marked increase in reactive oxygen species and their peroxidation products can act as a second messenger, activating redox sensitive transcription factors, and further amplifying the release of multiple proinflammatory factors, causing liver damage [22]. Pneumonia associated hypoxia is an important factor causing secondary liver injury in COVID19 patients.

\section{Drug induced liver injury}

Moderate microvascular steatosis [23, 24] with mild hepatic inflammation in liver pathology (postmortem) COVID-19 patients indicates the possibility of mitochondrial damage due to drug induced liver injury. Previously, it has been reported that patients suffering from viral infections, such as hepatitis $\mathrm{C}$ and human immunodeficiency viruses, are more prone to developing drug-induced liver injury (DILI) 
[25]. It is unclear whether COVID-19 infection also predisposes to DILI. MAFLD, a recently recognised comorbidity factor for disease progression in COVID-19, can sensitize the liver for hepatotoxicants such as acetaminophen, used as antipyretic for symptomatic treatment. [26]. Also, patients suffering from COVID-19 were shown to have an increased serum levels of monocyte chemoattractant protein-1 (MCP1 ) which is a chemokine known to exacerbate steatohepatitis.

Actemra (tocilizumab) - an interleukin-6 inhibitor - has been approved in China for the treatment of COVID-19 patients with serious lung damage and accompanying elevated blood levels of IL-6 [27]. The use of these immune suppressive therapy in other disease conditions has been shown to result in fulminant hepatic failure due to hepatitis $B$ virus reactivation in patients with chronic hepatitis $B$ infection [28]. A number of therapeutic agents, namely chloroquine, hydroxychloroquine, remdesivir, favipiravir, lopinavir/ritonavir and traditional Chinese medicines (TCM) are being used in the treatment of COVID-19 with variable degree of hepatotoxicity. (Table 1) [29-32] A recent study on 417 patients with COVID-19, use of lopinavir/ritonavir increased the odds of liver injury (ALT and/ or AST $>3 \times$ ULN; ALP, GGT, and/or TBIL $>2 \times$ ULN) by 7-fold [12]. On $1^{\text {st }}$ May 2020, Remdesivir, a nucleotide ribonucleic acid (RNA) polymerase inhibitors, has been authorized by the U.S. Food and Drug Administration (FDA) under Emergency Use Authorization (EUA) for emergency treatment for those hospitalized with severe COVID-19 disease. Liver function derangement, which lead to drug withdrawal, has been reported in patients treated with Remdesivir [33].
The severity and frequency of liver injury correlate with the severity of COVID-19; those with disease progression have severe liver injury more frequently $[2,10,11,13,34]$. In one recent study, it was found that after adjustment for age, sex, epidemiological history, liver comorbidities, and initial symptoms, liver injury(ALT and/or AST $>3 \times$ ULN; ALP, GGT, and/or TBIL $>2 \times$ ULN) had an odds ratio of 9.04 (95\% CI 3.19-25.6) for developing severe COVID-19 [12]. Emerging data suggest that pre-existing CLD occurred in $2-11 \%$ of patients with COVID-19 and patients with underlying metabolic (dysfunction) associated fatty liver disease (MAFLD) are more susceptible to disease progression with more prolonged viral shedding [35].

Figure 1 shows an approach to elevated liver enzymes in a COVID-19 patient.

\section{Recommendations}

(1) Expectant treatment with constant liver function tests is adequate in most instances [Class I, level C].

(2) All COVID-19 patients should be screened for hepatitis $B$ surface antigen and nucleos(t)ide analogues should be prescribed, especially in those planned for treatment with IL-6 monoclonal antibody or other immunosuppressive therapy [Class I, level C].

(3) Patients with pre-existing chronic liver disease, including non-alcoholic fatty liver disease should have liver function test monitored closely [Class I, level C].

Table 1 Investigational Treatment for COVID-19

\begin{tabular}{|c|c|c|c|c|}
\hline $\begin{array}{l}\text { Agent } \\
\text { (Route/Mechanism) }\end{array}$ & $\begin{array}{l}\text { Abnormal liver functions in } \\
\text { COVID-19 Trials }\end{array}$ & Comments & Suggestions & References \\
\hline $\begin{array}{l}\text { Remdesivir } \\
\text { (IV/nucleotide analogue) }\end{array}$ & $\begin{array}{l}21-24 \% \\
4 \% \text { drug discontinuation } \\
\text { Single arm study }\end{array}$ & $\begin{array}{l}\text { Over incidence } \\
\text { Not significantly higher than } \\
\text { COVID-19 subjects not on } \\
\text { remdesivir }\end{array}$ & $\begin{array}{l}\text { Careful monitoring, } \\
\text { stopped when ALT/ } \\
\text { AST }>5 \times \text { ULN, biliru- } \\
\text { bin }>2 \times \text { ULN }\end{array}$ & Grein J, et al. [29] \\
\hline $\begin{array}{l}\text { Lopinavir-ritonavir } \\
\text { (Oral/HIV protease inhibitor) }\end{array}$ & $\begin{array}{l}3-10 \% \text { overall } \\
\text { Grade } 3-42 \% \text { vs } 4 \% \text { com- } \\
\quad \text { pared to placebo }\end{array}$ & $\begin{array}{l}\text { Over incidence } \\
\text { Not significantly higher } \\
\text { than Covid-19 on placebo } \\
\text { placebo }\end{array}$ & $\begin{array}{l}\text { Careful monitoring, } \\
\text { stopped when ALT/ } \\
\text { AST }>5 \times \text { ULN, biliru- } \\
\text { bin }>2 \times \text { ULN }\end{array}$ & Cao B, et al. [30] \\
\hline $\begin{array}{l}\text { Hydroxycholoroquine / } \\
\text { Chloroquine } \\
\text { (Oral) }\end{array}$ & $\begin{array}{l}26 \% \text { vs } 20 \% \text { (placebo) in } \\
\text { combination with Azithro- } \\
\text { mycin }\end{array}$ & $\begin{array}{l}\text { Over incidence } \\
\text { Not significantly higher than } \\
\text { Covid-19 on placebo }\end{array}$ & $\begin{array}{l}\text { Careful monitoring, } \\
\text { stopped when ALT/ } \\
\text { AST }>5 \times \text { ULN, biliru- } \\
\text { bin }>2 \times \text { ULN }\end{array}$ & Gautret P, et al. [31] \\
\hline $\begin{array}{l}\text { Azithromycin } \\
\text { (Oral) }\end{array}$ & $\begin{array}{l}26 \% \text { vs } 20 \% \text { (placebo) } \\
\text { In combination with } \\
\text { Hydroxycholoroquine } \\
\text { /Chloroquine }\end{array}$ & $\begin{array}{l}\text { Over incidence } \\
\text { Not significantly higher than } \\
\text { Covid-19 on placebo }\end{array}$ & $\begin{array}{l}\text { Careful monitoring, } \\
\text { stopped when ALT/ } \\
\text { AST }>5 \times \text { ULNl, biliru- } \\
\text { bin }>2 \times \text { ULN }\end{array}$ & Gautret P, et al. [31] \\
\hline $\begin{array}{l}\text { Favipiravir } \\
\text { (Oral/RNA polymerase } \\
\text { inhibitor) }\end{array}$ & $\begin{array}{l}2.9 \% \text { vs } 6.6 \% \text { (lopinavir/ } \\
\text { ritonavir) }\end{array}$ & $\begin{array}{l}\text { Over incidence } \\
\text { Not significantly higher than } \\
\text { COVID - } 19 \text { subjects not on } \\
\text { flavpiravir }\end{array}$ & $\begin{array}{l}\text { Careful monitoring, } \\
\text { stopped when ALT/ } \\
\text { AST }>5 \times \text { ULN, biliru- } \\
\text { bin }>2 \times \text { ULN }\end{array}$ & Cai Q, et al. [32] \\
\hline
\end{tabular}


Fig. 1 Evaluation of COVID19 patient with elevated liver enzymes

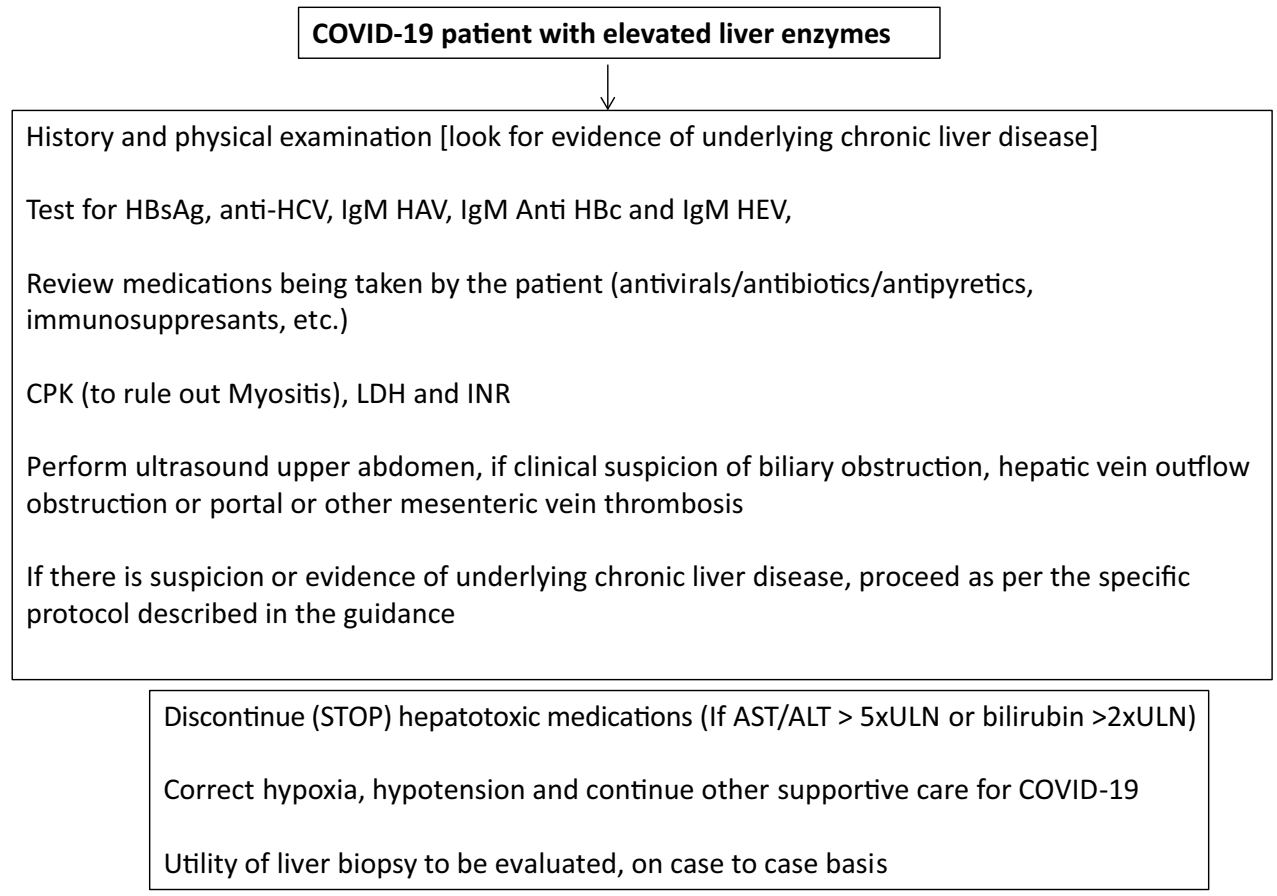

(4) Drug-induced liver injury during the treatment of COVID-19 should not be ignored and needs to be carefully investigated [Class I, level C].

(5) Investigational treatments for COVID-19 may cause elevation of serum aminotransferases, but the overall incidence is not significantly different from placebo or general COVID-19 patients. Close monitoring of liver function tests is recommended in these patients [Class I, level B].

(6) Patients with chronic liver disease should be regarded as risk factor for COVID-19 disease progression and should be prioritised as candidate for drug trial [Class I, level C].

(7) Close monitoring of liver function in patients, especially those with CLD, treated with Remdesivir; patients with decompensated CLD and those with ALT $>5$ times upper limit of normal, should not be treated with Remdesivir [Class I, level C].

\section{Conduct of elective medical practice-consultation, imaging, liver biopsy, endoscopy-[Piratvisuth Teerha (Thailand), Sarin Shiv (India)]}

\section{Consultations (outpatients and inpatients)}

Health care workers and other hospital staff are at risk for COVID-19. Healthcare workers with SARS-CoV-2 may spread the virus to patients and to each other, and should stay away from inpatient and outpatient work until approval of clinical duty resumption issued by local health authorities is obtained. Minimizing interactions among healthcare workers and between healthcare workers and patients is critical to reduce the spread of SARS-CoV-2. Minimizing the transport of patients within and between healthcare facilities could reduce the spread of SARS-CoV-2.

\section{Recommendations}

(1) Conduct outpatient clinic and inpatient rounds of nonCOVID patients with the minimum number of personnel needed for care provision at a given time. [Class I, level C]

(2) Discourage in-person multidisciplinary rounds with dietary, pharmacy, social work, and care coordination staff. [Class I, Level C]

(3) Assess whether the patient can have future encounters by phone or telemedicine and encourage early monitoring by these means to reduce in-person visits. [Class I, level C]

(4) Consider seeing in person only new patients with urgent issues and clinically significant liver disease (e.g., jaundice, elevated ALT or AST $>500 \mathrm{U} / \mathrm{L}$, recent onset of hepatic decompensation). [Class I, level C]

(5) Assess the albumin infusion needs to a patient. If patient requires twice a week or more often albumin, one should consider admitting such a patient. [Class $\mathrm{IIb}$, level C]. Oral intake of foods containing high albumin or oral preparations of albumin need to be evaluated in the interim period. 


\section{Imaging}

Chronic liver disease particularly in patients with cirrhosis is a major risk for hepatocellular carcinoma. Interval HCC surveillance can facilitate detection of early HCC [36]. Although HCC surveillance with ultrasound and AFP every 6 months is recommended, there should be a balance between the risk of a delayed HCC detection and the risk of spreading COVID-19 during the process of HCC surveillance. There was a report of similarly overall survival with 12-monthly HCC surveillance [37]. Therefore, delaying HCC surveillance is reasonable during the COVID-19 pandemic.

\section{Recommendations}

(1) For stable HCC patients without COVID-19, continue monitoring with telemedicine and local AFP. [Class I, level C]

(2) Continue $\mathrm{HCC}$ surveillance in high risk subjects (cirrhosis, chronic hepatitis B) for HCC, adhering to the planned schedule if possible. A delay of 2 months is acceptable after discussing the risks and benefits of delaying surveillance with the patient. [Class I, level C]

(3) Patients with increased risk of HCC such as elevation of AFP or presence of liver nodule should be prioritized for HCC-surveillance. [Class I, level C]

(4) Transportation of COVID-19 patients for imaging study such as ultrasound should be avoided unless there is a presence of strong indication. [Class 1, level C]

\section{Liver biopsy}

The angiotensin-converting enzymes (ACE2), the receptor for COVID-19 viral entry, have been shown to be expressed on cholangiocytes [14]. Liver biopsy may have a risk of COVID-19 viral transmission.

\section{Recommendations}

(1) Among patients not infected with COVID-19, cancel all elective/non-urgent liver biopsy procedures. [Class I, level C]

(2) Liver biopsy could be performed in patients not infected with COVID-19 in circumstances where biopsy findings will have a major impact on the management like suspected autoimmune flare or rejection. [Class I, level C]

(3) Liver biopsy should not be done in COVID-19 infected patients. [Class I, level C]

\section{Endoscopy}

Variceal bleeding is one of the common and important complications in cirrhotic patients with portal hypertension. Surveillance for high risk varices is recommended for considering primary prophylaxis in patients with high risk of variceal bleeding [38]. As COVID-19 virus has been detected in saliva and feces, endoscopy can be a risk for COVID-19 transmission [39, 40]. In addition, upper endoscopic procedure could be aerosol generating [41].

\section{Recommendations}

(1) Elective or non-urgent endoscopy should be deferred. Non-invasive tool such as LSM, Fib-4 or platelet count may be used to identify patients with high risk of variceal bleeding (Baveno VI criteria) [42]. [Class I, level C]

(2) Urgent or emergency endoscopy procedures for upper or lower GI bleeding and ascending cholangitis should be performed. [Class 1, level C]

(3) All health care workers involved with endoscopic procedures in confirmed or high risk of COVID-19 patients should wear PPE including N95 mask with face shield, water impervious long-sleeved gown and gloves; whereas for endoscopic procedures in a patient at low risk of COVID-19 healthcare workers should wear N95 with face shield, water impervious longsleeved gown and gloves. [Class I,Level C]

\section{Emergency services in hepatology: [Gani Rino (Indonesia), Kadir Dokmeci (Turkey)]}

SARS-CoV-2 virus use ACE2 receptor to enter the cells. The ACE2 receptors can be found not only in the airway system but also in gastrointestinal organs. SARS-CoV-2 virus are detected in faecal samples [43] raising the possibility of fecal transmission. Gastrointestinal bleeding or signs of cholangitis can complicate the management of patient with Covid-19 and endoscopy may be considered of high-risk because high concentration of Sars-Cov-2 virus in pulmonary and gastrointestinal secretion [44]. Several societies such as The British Society of Gastroenterology and European Society of Gastrointestinal Endoscopy have released guidance for performing endoscopy in Covid-19 patients. They underline the prioritisation of cases to reduce the workload, minimize the potential exposure to health personnel and the chance of virus transmission. Proper PPE should be worn by all the health personnel and endoscopy should be performed only in urgent 
situation. Care must be taken in donning and doffing the PPE.

Intestinal evacuations, especially intestinal lavage are high risk procedures. In cirrhosis patient with liver encephalopathy or upper gastrointestinal bleeding, intestinal lavage from rectal approach should be discouraged and replaced by oral laxative.

\section{Recommendations}

(1) Postpone all elective/non-urgent procedures [Class I, Level C]

(2) Emergency procedures should be performed when needed, e.g., liver biopsy to rule out graft rejection or diagnose autoimmune hepatitis, therapeutic paracentesis, transjugular intrahepatic portosystemic shunt, endoscopy for variceal bleeding, band ligation, urgent biliary procedures for cholangitis and sepsis. [Class I, Level C]

(3) All healthcare workers involved with endoscopic and other emergency procedures in confirmed or at high risk of COVID-19 patients should wear N95 mask with face shield, water impervious long-sleeved gown and gloves. [Class I, level C]

\section{Management of liver transplantation and autoimmune diseases: [Strasser Simone(Australia), Wei Lai (China)]}

\section{Liver transplant}

The COVID-19 pandemic has had enormous impacts on the provision of liver transplantation (LT) around the world. The capacity to provide LT has been impacted severely due to reduced referrals of deceased donors and diversion of hospital and ICU resources to COVID-19 cases [45, 46]. Other impacts include the risk of LT recipients or live donors acquiring SARS-COV-2 infection during hospitalization and the possibility of transmission from an undiagnosed donor to a recipient or to healthcare workers.

In view of the limitations in access to personal protective equipment (PPE) and other resources during the pandemics, and transmission risks to patients and healthcare workers, governments in many countries have implemented restrictions on elective surgery. Liver transplant units around the world have observed significantly reduced transplant activity and needed to prioritize those patients at highest risk mortality if transplant procedure was delayed.

The impacts of COVID-19 in LT patients may differ if the infection is acquired in the perioperative or early post-transplant period when immunosuppressive levels are highest and potentially more severe COVID-19. On the other hand, some long-term post-transplant patients may also have many of the comorbidities, such as diabetes, hypertension, that have been associated with severe COVID-19 [47, 48]. There are also concerns that hospitalized immune suppressed patients may have prolonged viral shedding [49], posing a risk to contacts.

To date there have been few reports of the impacts of COVID-19 infection on LT recipients. Reports from transplant centers are emerging from China [50], Spain [51] and Italy [52]. Current evidence suggests that the profile of COVID-19 infection may be no worse in LT patients than in non-transplant patients and there may be lower risk of hyperinflammation, cytokine storm and severe lung injury seen in patients with severe respiratory-COVID-19 infection [43], suggesting that the presence of immunosuppressive therapy may modify the host response to infection. However, high mortality rates in long-term transplant recipients have been reported from some transplant centers [51-53], particularly in patients on low immunosuppression and with the metabolic comorbidities that predict severe disease and mortality in non-transplant patients. Recommendations regarding the impact of COVID-19 on LT services and the care of LT patients have emerged from various transplant centers [54-57].

\section{Recommendations}

(1) Consider limiting LT to emergency and urgent cases only (eg acute liver failure, high MELD, high risk of HCC progression) according to local resource limitations and status of the outbreak. [Class I, level C]

(2) Look for presence of SARS-COV-2 RNA in nasopharyngeal swab or bronchoalveolar lavage fluid of donor or evidence of COVID-19 infection on chest CT scan prior to organ procurement. Negative test results may not exclude infection. [Class I, Level C]

(3) Avoid use of deceased or live donors with evidence of COVID-19 infection. [Class I, level C]

(4) Assessment of LT recipients for COVID-19 infection, particularly in the presence of symptoms or contact with a known COVID-19 case. Risks of LT during infection must be balanced against risk of delaying LT, and the risks to healthcare workers. [Class I, level C]

(5) Consider specific consent of all patients on the LT waiting list regarding the impact of the COVID-19 pandemic on their situation. [Class I, level C]

(6) Patients who undergo liver transplantation during the COVID-19 pandemic should be managed with standard immunosuppression protocols [Class I, level C]

(7) Immunosuppression doses should not be reduced in long-term LT patients in the absence of COVID-19 infection. Reduction of routine immunosuppression 
risks an episode of allograft rejection. [Class I, level C]

(8) Reduction of immunosuppression may be considered in patients diagnosed with moderate COVID-19 infection. Immunosuppression should be reduced in patients with lymphopenia, fever, or worsening pneumonia. Adrenal insufficiency must be avoided and allograft function must be carefully monitored. [Class I, level C]

(9) Transplant patients who develop severe COVID-19 should be managed according to local protocols. Drug-drug interactions must be considered. [Class I, level C]

(10) Transplant centers should assist their patients to avoid COVID-19 infection yet maintaining transplant follow-up by reinforcement of hand hygiene, social isolation and physical distancing recommendations and avoidance of nosocomial transmission. Disease control and follow-up should be maintained through altered pathways including telehealth/telephone consultation and local blood testing. Immediate medical attention must be provided when indicated. [Class I, level C]

(11) All LT recipients should receive vaccination against influenza and pneumococcal infection. [ Class I, Level B]

\section{Autoimmune diseases}

The impact of COVID-19 infection on patients with autoimmune liver diseases (AILD), including autoimmune hepatitis, primary biliary cholangitis and primary sclerosing cholangitis, is unclear. However, there are no data to suggest these patients, even if immunosuppressed, are at increased risk of severe infection. There is a significant risk of under-treatment if diagnosis is delayed in patients with new-onset disease or if doses of immunosuppressive medications are reduced based on theoretical concerns that immunosuppressed patients are at particular risk. Furthermore, clinicians should aim to provide diagnostic investigations, therapeutic procedures and long-term monitoring through the pandemic as interruptions may have significant impacts on long-term outcomes. Some guidance regarding the care of patients with AILD from experienced centers heavily impacted by COVID-19 is emerging [58]. Registry-level data are anticipated in the future.

\section{Recommendations}

Patients with AILD should be diagnosed and managed according to standard guidelines. [Class I, level C]

In patients without COVID-19 infection, maintenance immunosuppressive medication doses should be main- tained at lowest effective doses and should not be reduced or ceased. [Class I, level C]

Patients with AILD and mild COVID-19 infection should continue their usual immunosuppression and other medications. [Class I, level C]

Patients with AILD and severe COVID-19 infection should be managed according to local protocols. Corticosteroids should not be discontinued, stress-doses may be required. [Class I, level C]

Clinicians should assist their patients to avoid COVID19 infection by reinforcement of hand hygiene, social isolation and physical distancing recommendations and avoidance of nosocomial transmission. Disease control and follow-up should be maintained through altered pathways including telehealth/telephone consultation and local blood testing. Immediate medical attention must be provided when indicated. [Class I, level C]

Patients with AILD should receive vaccination against influenza and pneumococcal infection. [Class I, level B]

\section{Patients with hepatocellular carcinoma: Laurentius Adrianto Lesmana (Indonesia), Tatsuo Kanda (Japan), Masao Omata (Japan)}

One of the cell surface receptor candidates for SARS-CoV-2 is angiotensin-converting enzyme 2 (ACE2), which exists in human airway epithelial cells as well as cholangiocytes and hepatocytes. Therefore, this virus and/or COVID-19 may affect the natural course of patients with hepatocellular carcinoma (HCC).

\section{Screening for HCC in stable outpatients with chronic viral hepatitis or cirrhosis}

It is important to avoid or reduce the opportunity to contact with SARS-CoV2 infected patients. Although the duration of follow-up for patients depends on the local epidemic situation of COVID-19, delay of 2-3 months seems to be reasonable even in higher risk patients. If possible, computed tomography (CT) of chest may also be performed when abdominal $\mathrm{CT}$ is performed as chest CT examination can accidentally diagnose COVID-19. [59] Telemedicine and phoned prescription may be useful to avoid "face to face" contact. [60]

\section{Recommendations}

(1) Avoid frequent visits to hospitals and postpone patient visits for screening HCC. [Class I, level C]

(2) Refer to imaging guidance for HCC screening 


\section{Treatment for HCC patients}

In general, APASL HCC guidelines [61] should be observed. However, at present, it is not completely ruled out that transfusion transmits SARS-CoV2 [62]. Clinicians should pay careful attention to the blood supply in HCC resection, as most blood donation centers in many endemic areas around the world have closed [63]. Transplantation also requires long-term use of immunosuppressants, which may be a risk for COVID-19. Screening for SARS-CoV-2 using new diagnostic tools [64] should be carefully performed in both donor and recipient. After transplantation, careful follow-up should also be paid [65].

The effects of COVID-19 in patients with HCC is not known. In general, cancer patients are more susceptible to infections than individuals without cancer, due to systemic immune suppressive state due to malignancy and anticancer treatments [66]. Therefore, these patients might be at increased risk of COVID-19 and have a poorer prognosis. In a recent study on 1590 COVID-19 cases (admitted for acute respiratory COVID-19) from 575 hospitals in China, it was found that $18(1 \%$; $95 \%$ CI $0.61-1.65)$ had a history of cancer (although none of the patients had history of HCC). This figure seemed to be higher than the incidence of cancer in the overall Chinese population [285.83 (0.29\%) per 100 000 people [2015 cancer epidemiology statistics], suggesting that cancer patients were more susceptible to infection [67]. Twenty five percent of cancer patients had chemotherapy or surgery in the last 1 month. Patients with cancer were observed to have a higher risk of severe events. Also, patients with cancer deteriorated more rapidly than those without cancer [median time to severe events: 13 vs 43 days (20-not reached), p < 0.0001; Hazard ratio 3.56 (95\% CI 1.65-7.69), after adjusting for age]. After adjusting for other risk factors, including age, smoking history, and other comorbidities, patients who had undergone chemotherapy or surgery within last 1 month had higher odds of developing severe events [OR $=5.34(1.80-16.18) ; p=0.0026]$ as compared to patients who had not undergone such procedure within the last 1 month. However, concerns remain regarding generalizability of the study, with such a small sample size with a large amount of heterogeneity (various cancer types with different biological behaviors, highly variable disease courses, and diverse treatment strategies). However, the specific clinical strategies for patients with HCC remain unclear. This is a yet published scenario with scarce data. It is unknown whether patients with HCC are at increased risk for severe COVID-19 by virtue of their malignancy. The effect of TACE, immunotherapy (Check point inhibitors) and kinase inhibitors on risk of getting COVID-19 and developing severe COVID-19 if infected remains unknown.

Stress related to isolation and fear of COVID-19, might result in a surge of alcohol intake in patients with $\mathrm{HCC}$ and should be avoided [68]. The risk of fatality has been related to preexisting comorbid conditions, such as cardiovascular disease, diabetes, chronic respiratory disease, hypertension which need to be carefully managed [69].

In HCC patients with COVID-19, COVID-19 should initially be treated. Attention should be paid to immunosuppressants and drug-drug interactions in $\mathrm{HCC}$ patients, as most had advanced liver diseases like cirrhosis.

\section{Recommendations}

(1) For newly diagnosed HCC patients, postponing of elective transplant, resection surgery, or radiotherapy may be considered. [Class IIa, level C]. Ablative procedures, transcatheter arterial chemo embolization, kinase inhibitors or immunotherapy may be initiated. Change of immunotherapy schedules to 4-6 weeks may be considered. [Class IIA, level C]

(2) Among uninfected HCC patients who are already on treatment, HCC treatment should proceed as deemed appropriate. [Class I, level C]. Uninfected patients already on kinase inhibitors may continue treatment. Change of immunotherapy schedules to 4-6 weeks may be considered. [Class IIa, level C]

(3) Avoid excessive alcohol intake. [Class I, level C]

(4) Careful management of comorbid conditions such as cardiovascular diseases, diabetes mellitus and hypertension [Class I, level C]

(5) If HCC patients get infected with COVID-19, withhold immunotherapy directed towards HCC. [Class I, level C]

\section{Chronic liver diseases as risk factors for covid-19 disease progression: [Kao Jia-Horng (Taiwan), Yokosuka Osamu (Japan)]}

There is no evidence suggesting patients with stable chronic liver diseases such as hepatitis $\mathrm{B}$, hepatitis $\mathrm{C}$, primary biliary cholangitis, primary sclerosing cholangitis, autoimmune hepatitis or MAFLD have increased susceptibility to SARS-CoV-2 infection. However, advanced cirrhosis, HCC, autoimmune liver diseases, and post liver transplant patients may be more susceptible to COVID-19 infection as they are immuno-compromised.

The interactions between chronic liver diseases and COVID 19 remain largely unknown. The prevalence of chronic liver disease in COVID-19 patients ranges from $2-11 \%$ [10]. At the time of this writing, there is limited Information regarding the impact of COVID-19 on patients with chronic liver diseases. In an early pooled analysis of 6 studies [4 studies compared CLD in severe vs non severe 
cases (total 702 patients with 371 (52.8\%) having severe disease); and 2 studies compared rate of CLD in non-survivors vs survivors (total 202 patients with 100 (49.5\%) being non survivors), it was concluded that CLD was not associated with increased odds of severe form of COVID-19 or with increased odds of mortality from COVID-19 [70]. A recent study including 15 patients with chronic hepatitis $\mathrm{B}$ and COVID-19 showed that they had higher total bilirubin levels, more severe disease course ( $46.7 \%$ vs. $24.1 \%)$, and a higher mortality rate (13.3\% vs. $2.8 \%$ ) compared with those without HBV infection [71], suggesting COVID-19 patients with HBV co-infection may be easier to develop liver injury with more adverse outcomes and mortality. However, this should be carefully examined because of the small number of hepatitis B patients in the report. The number of fatal COVID 19 patients in Europe where the hepatitis B is not endemic is not lower than in Chinese patients. In contrast, chronic viral hepatitis appears not to increase the risk of a severe course of COVID-19 [72]. In the meantime, a study on 202 COVID-19 patients revealed that 76 MAFLD patients had a higher risk of COVID-19 disease progression, higher likelihood of abnormal liver function from admission to discharge and longer viral shedding time when compared to non-MAFLD subjects [35]. The liver contains the largest number of macrophages (Kupffer cells) in the body and is a potent cytokine producer. Impaired hepatic innate immune status might play a critical role in COVID-19 outcome. In MAFLD patients, impaired innate immunity (manifested by derailed functional diversity of macrophages, imbalance between inflammation promoting M1 macrophages and inflammation suppressing M2 macrophages) and increased production of pro-inflammatory cytokines like TNF- $\alpha$ by adipose cells and Kupffer cells, may predispose MAFLD patients to severe COVID-infection [35]. It is unclear if the risk is specific to MAFLD or to co-existing metabolic risk factors such as cardiovascular disease, diabetes mellitus, and obesity, which are known to be associated with COVID-19 severity.

Effects of COVID-19 infection in patients with decompensated cirrhosis are unknown. Whether acute-on-chronic liver failure can be precipitated by COVID-19 remains unknown. It is important to evaluate patients with liver disease for COVID-19 if they develop new onset encephalopathy or other acute decompensation.

Currently, there is no specific treatment for liver dysfunction in COVID-19 related liver injury. We should target the SARS-CoV-2 infection and maintain the original therapy for underlying chronic liver diseases.

\section{Recommendations}

(1) Patients with liver cirrhosis/liver cancer/ on immunosuppressive therapy (AIH or post LT) might be more susceptible to COVID-19 infection because of their systemic immune compromised status [Class IIA, level C].

(2) Patients with stable chronic hepatitis B or C or MAFLD or cholestatic liver diseases may have increased susceptibility to SARS-CoV-2 infection. [ Class IIA level C]

(3) Chronic HBV, MAFLD and cirrhosis are possible risk factors for severe COVID19 [Class I, level B]. Patients with advanced liver diseases should carefully observe the rules of physical distancing to avoid COVID 19. [Class I, level C]

(4) Among COVID-19 non-infected patients, continue treatment for hepatitis B and hepatitis $C$ if already on treatment. For newly diagnosed patients, proceed with antiviral treatment of hepatitis $\mathrm{B}$ and $\mathrm{C}$ as clinically warranted. [Class I, level C]

(5) Among infected patients, continue treatment for hepatitis $B$ and hepatitis $C$ if already on treatment. Initiating treatment of hepatitis B in a patient with COVID-19 is not routinely warranted but should be considered if there is clinical suspicion of a hepatitis B flare or patient is planned for treatment with IL-6 monoclonal antibody or other immunosuppressive therapies. Initiating treatment of hepatitis $\mathrm{C}$ in a patient with COVID-19 is not routinely warranted. [ Class I, level C]

(6) Discuss with the patients the diagnosis and management of advanced liver disease and document it. [Class I, level C]

\section{Conduct of clinical trials: [Sollano Jose(Philippine), Yang Jin Mo (South Korea), Gregory Cheng (Macau SAR, China)]}

To date, a lot of the clinical trials involving liver diseases, such as viral hepatitis, fatty liver and liver cancer, are conducted in Asia-Pacific region [73]. Many of these trials are meant for global registration and hence need to comply not only with local authority but also US FDA and European Medicines Agency. With the need for social distancing, quarantine and isolation implemented in response to pandemic COVID-19, site visits, trial medication administration and supply chain, samples and data collection and monitoring related to the conduct of clinical trials are facing great challenges $[74,75]$. For many studies, screening of new subjects cannot be proceeded. Patients already in screening or on study are to continue treatment. To strike a balance between trial integrity and safety of patients, investigators and medical research personnel maintaining compliance with specific 
guidance would be of utmost importance. In this connection, timely modifications of protocol in accordance to local environment and the nature of the trial might be required. With the widely available audio-visual real time contact via internet, the implementation of electronic informed consent, remote safety, performance outcome and interview-based clinician-reported outcome assessments would minimize the impact of COVID-19 pandemic to trial participants and studies. Speedy home delivery would ensure continuing use of the medications. Certain conditional adjustment with approval of the IRB could also be adopted as in reality, protocol deviation is almost unavoidable.

\section{Recommendations}

(1) Careful evaluation of the operational capability of the site in terms of adequate PPE for medical personal, extra checking on travel and contact history, temperature test and even throat swab test for SARS-CoV2. [ Class I, level C]

(2) Communicate with sponsor to evaluate how alternative processes for safety assessments and study procedures such as phone contact, virtual visit, alternative location for local lab test or imaging scan could be implemented for the subjects who cannot attend the scheduled visits at site. Investigators would make treatment decisions upon review of all available safety information and discussion with study medical monito. [Class I, level C]

(3) Arrange home delivery of medication to subjects, whom investigators considered safe to continue treatment. If the supply chain or shipment of investigational product (IP) to the site is affected, site-to-site transfer of IP, sponsor to patient transfer of IP (bypassing clinical trial pharmacies) or commercially purchasing the approved product could be implemented. IP administration such as infusion could be done via home nursing or local healthcare providers. [Class I, level C]

(4) Document a listing of all study visits or procedures that are deviations from the protocol due to COVID19 pandemic and submit the report with deviation reason to the IRB. The listing could simplify the report of protocol deviation (PD) since a large number of $\mathrm{PD}$ is expected to occur. [Class I, level C]

(5) Notify local regulations and IRB of the contingency measures for the COVID-19 pandemic and make sure the measures are acceptable. For study-wide change in protocol conduct including but not limited to implementing remote visits and IP home delivery, protocol amendment should be submitted to IRB for approval. In addition, trial participants should be made aware of and in agreement with the changes. [Class I, level C]
APASL COVID-19 Task-force members (in alphabetical order): Cheng Gregory, Faculty of Health Science, Macau University (Macau SAR, China) and Humanity and Health Medical Group, Hong Kong SAR, China). Email: gregory.cheng@hnhmgl.com. Gani Rino, Department of Internal Medicine, Cipto Mangunkusumo Hospital, University of Indonesia, Jakarta, Indonesia. Email: personaly@yahoo.com. Guan Richard, Mount Elizabeth Medical Centre, Singapore 228510. Email: rgyc5@singnet.com.sg. Hasmik Ghazinyan, Hepatological Department, Norq Clinical Hospital of Infectious Diseases, Armenia. Email: ghazinian@ gmail.com. Kadir Dokmeci, Department of Gastroenterology, Ankara University School of Medicine, Ankara, Turkey. Email: akdokmeci@hotmail.com. Tatsuo Kanda, Division of Gastroenterology and Hepatology, Department of Medicine, Nihon University School of Medicine, Tokyo, Japan. Email: kanda2t@ yahoo. co.jp. Kao Jia-Horng, Graduate Institute of Clinical Medicine and Hepatitis Research Center, National Taiwan University College of Medicine, National Taiwan University Hospital, Taipei, Taiwan. Email: kaojh@ ntu.edu.tw. Lau George, Humanity and Health Clinical Trial Center, Humanity \& Health Medical Group, Hong Kong SAR, China or The Fifth Medical Center of Chinese PLA General Hospital, Beijing 100039, China. Email: gkklau@hnhmgl.com/gkklau@ netvigator.com. Laurentius Adrianto Lesmana, Digestive Disease and GI Oncology Center, Medistra Hospital, University of Indonesia, Jakarta, Indonesia. Email: 1lesmana.id@ gmail.com. Merican Ismail, Mahsa University, Selangor; Prince Court Medical Centre, Kuala Lumpur, Malaysia. Email: ismailmerican@gmail.com. Masao Omata, Department of Gastroenterology, Yamanashi Prefectural Central Hospital, Kofu-city, Yamanashi, Japan. The University of Tokyo, Tokyo, Japan. Email: aug8808@yahoo.co.jp. Payawal Diana, Department of Hepatology, Cardinal Santos Medical Center, Manila, Philippines. Email: dianapayawal@yahoo.com. Piratvisuth Teerha, NKC Institute of Gastroenterology and Hepatology, Prince of Songkla University, Songkhla, Thailand. Email: teerha.p@psu.ac.th. Sarin Shiv, Department of Hepatology, Institute of Liver and Biliary Sciences, New Delhi, India. Email: sksarin@ilbs. in. Sharma Manoj, Department of Hepatology, Institute of Liver and Biliary Sciences, New Delhi, India. Email: manojkumardm@gmail.com. Sollano Jose, Department of Medicine, University of Santo Tomas, Manila, Philippines. Email: jsollano@i-manila.com. ph. Strasser Simone, AW Morrow Gastroenterology and Liver Centre, Royal Prince Alfred Hospital, Missenden Rd Camperdown NSW 2050. Email: simone. strasser@health.nsw.gov.au. Tanwandee Tawesak, 
Division of Gastroenterology, Department of Medicine, Siriraj Hospital,Mahidol University, Bangkok 10700, Thailand. Email: tawesak@ gmail.com. Wasim Jafri, Department of Medicine, Aga Khan University and Hospital, Karachi, Pakistan. Email: wasim.jafri@aku. edu. Wei Lai, Beijing Tsinghua Chang Gung Hospital, Changping District, Beijing, China. Email: weilai@ mail.tsinghua.edu.cn. Yang Jin Mo, Department of Medicine, Catholic University of Korea, South Korea. Email: jmyangdr@catholic.ac.kr. Yokosuka Osamu, Department of Gastroenterology and Nephrology, Graduate School of Medicine, Chiba University, Chiba, Japan. Email: yokosukao@faculty.chiba-u.jp.

\section{Compliance with ethical standards}

Conflict of interest The authors declare that they have no conflict of interest.

\section{References}

1. https://www.who.int/publications-detail/global-surveillan ce-for-human-infection-with-novel-coronavirus-(2019-ncov). Accessed 16 Apr 2020.

2. Shiffman RN, Shekelle P, Overhage JM, Slutsky J, Grimshaw J, Deshpande AM. Standardized reporting of clinical practice guidelines: a proposal from the Conference on Guideline Standardization. Ann Intern Med. 2003;139:493-8.

3. Rothe C, Schunk M, Sothmann P, Bretzel G, Froeschl G, Wallrauch C, et al. Transmission of 2019-n CoV infection from an asymptomatic contact in Germany. N Engl J Med. 2020;382(10):970-1.

4. Sanche S, Lin YT, Xu C, Romero-Severson E, Hengartner N, $\mathrm{Ke}$ R. High contagiousness and rapid spread of severe acute respiratory syndrome coronavirus 2. Emerg Infect Dis. 2020. https://doi.org/10.3201/eid2607.200282 (Epub ahead of print).

5. Fu L, Wang B, Yuan T, Chen X, Ao Y, Fitzpatrick T, et al. Clinical characteristics of coronavirus disease 2019 (COVID19) in China: a systematic review and meta-analysis. J Infect. 2020. https://doi.org/10.1016/j.jinf.2020.03.041 (Epub ahead of print).

6. Luo S, Zhang X, Xu H. Don't overlook digestive symptoms in patients with 2019 novel coronavirus disease (COVID-19). Clin Gastroenterol Hepatol. 2020. https://doi.org/10.1016/j. cgh.2020.03.043 (Epub ahead of print).

7. https://www.cdc.gov/coronavirus/2019-ncov/community/organ izations/cleaning-disinfection.html. Accessed 16 Apr 2020.

8. Zheng Z, Peng F, Xu B, Zhao J, Liu H, Peng J, et al. Risk factors of critical \& mortal COVID-19 cases: a systematic literature review and meta-analysis. J Infect. 2020. https://doi. org/10.1016/j.jinf.2020.04.021 (Epub ahead of print).

9. Ji D, Zhang D, Xu J, Chen Z, Yang T, Zhao P, et al. Prediction for progression risk in patients with COVID-19 pneumonia: the CALL score. Clin Infect Dis. 2020. https://doi.org/10.1093/cid/ ciaa414 (Epub ahead of print).

10. Xu L, Liu J, Lu M, Yang D, Zheng X. Liver injury during highly pathogenic human coronavirus infections. Liver Int. 2020. https ://doi.org/10.1111/liv.14435 (Epub ahead of print).
11. Wang D, Hu B, Hu C, Zhu F, Liu X, Zhang J, et al. Clinical Characteristics of 138 Hospitalized Patients With 2019 Novel Coronavirus-Infected Pneumonia in Wuhan, China. JAMA. 2020. https://doi.org/10.1001/jama.2020.1585 (Epub ahead of print).

12. Cai Q, Huang D, Yu H, Zhu Z, Xia Z, Su Y, et al. Characteristics of liver tests in COVID-19 patients. J Hepatol. 2020. https://doi. org/10.1016/j.jhep.2020.04.006.

13. Wander P, Epstein M, Bernstein D. COVID-19 presenting as acute hepatitis. Am J Gastroenterol. 2020. https://doi. org/10.14309/ajg.0000000000000660 (Epub ahead of print).

14. Chai X, Hu L, Zhang Y, Han W, Lu Z, Ke A, et al. Specific ACE2 expression in cholangiocytes may cause liver damage after 2019-nCoV infection. bioRxiv. 2020. https://doi. org/10.1101/2020.02.03.931766.

15. Zhao B, Ni C, Gao R, Wang Y, Yang L, Wei J, et al. Recapitulation of SARS-CoV-2 infection and cholangiocyte damage with human liver ductal organoids. Protein Cell. 2020. https://doi. org/10.1007/s13238-020-00718-6 (Epub ahead of print).

16. Guan WJ, Ni ZY, Hu Y, Liang WH, Ou CQ, He JX, et al. Clinical characteristics of 2019 novel coronavirus infection in China. N Engl J Med. 2020;382(18):1708-20.

17. Yao XH, Li TY, He ZC, Ping YF, Liu HW, Yu SC, et al. A pathological report of three COVID-19 cases by minimally invasive autopsies. Zhonghua Bing Li Xue Za Zhi. 2020;49:E009 (in Chinese).

18. Polakos NK, Cornejo JC, Murray DA, Wright KO, Treanor JJ, Crispe IN, et al. Kupffer cell dependent hepatitis occurs during influenza infection. Am J Pathol. 2006;168(4):1169-78.

19. Xu Z, Shi L, Wang Y, Zhang J, Huang L, Zhang C, Liu S, Zhao P, Liu H, Zhu L, Tai Y, Bai C, Gao T, Song J, Xia P, Dong J, Zhao J, Wang FS. Pathological findings of COVID-19 associated with acute respiratory distress syndrome. Lancet Respir Med. 2020. https://doi.org/10.1016/S2213-2600(20)30076-X (Epub ahead of print).

20. Jose RJ, Manuel A. COVID-19 cytokine storm: the interplay between inflammation and coagulation. Lancet Respir Med. 2020. https://doi.org/10.1016/S2213-2600(20),30216-2 (Epub ahead of print).

21. Tang N, Li D, Wang X, Sun Z. Abnormal coagulation parameters are associated with poor prognosis in patients with novel coronavirus pneumonia. J Thromb Haemost. 2020;18:844-7.

22. Zhang XJ, Cheng X, Yan ZZ, Fang J, Wang X, Wang W, et al. An ALOX12-12- HETE-GPR31 signaling axis is a key mediator of hepatic ischemia-reperfusion injury. Nat Med. 2018;24:73-83. https://doi.org/10.1038/nm.4451.

23. Xu Z, Shi L, Wang Y, Zhang J, Huang L, Zhang C, Liu S, Zhao P, Liu H, Zhu L, Tai Y, Bai C, Gao T, Song J, Xia P, Dong J, Zhao J, Wang FS. Pathological findings of COVID-19 associated with acute respiratory distress syndrome. Lancet Respir Med. 2020;8(4):420-2.

24. Tian S, Xiong Y, Liu H, Niu L, Guo J, Liao M, Xiao SY. Pathological study of the 2019 novel coronavirus disease (COVID-19) through postmortem core biopsies. Mod Pathol. 2020. https://doi. org/10.1038/s41379-020-0536-x (Epub ahead of print).

25. Boeckmans J, Rodrigues RM, Demuyser T, Piérard D, Vanhaecke T, Rogiers V. COVID-19 and drug-induced liver injury: a problem of plenty or a petty point? Arch Toxicol. 2020. https://doi. org/10.1007/s00204-020-02734-1 (Epub ahead of print).

26. Massart J, Begriche K, Moreau C, Fromenty B. Role of non-alcoholic fatty liver disease as risk factor for drug-induced hepatotoxicity. J Clin Transl Res. 2017;3(Suppl 1):212-32.

27. Cao X. COVID-19: immunopathology and its implications for therapy. Nat Rev Immunol. 2020. https://doi.org/10.1038/s4157 7-020-0308-3 (Epub ahead of print). 
28. Chen LF, Mo YQ, Jing J, Ma JD, Zheng DH, Dai L. Short-course tocilizumab increases risk of hepatitis $\mathrm{B}$ virus reactivation in patients with rheumatoid arthritis: a prospective clinical observation. Int J Rheum Dis. 2017;20(7):859-69.

29. Grein J, Ohmagari N, Shin D, Diaz G, Asperges E, Castagna A, et al. Compassionate use of remdesivir for patients with severe Covid-19. N Engl J Med. 2020. https://doi.org/10.1056/NEJMo a2007016.

30. Cao B, Wang Y, Wen D, Liu W, Wang J, Fan G, et al. A trial of lopinavir-ritonavir in adults hospitalized with severe Covid-19. N Engl J Med. 2020. https://doi.org/10.1056/NEJMoa2001282.

31. Gautret P, Lagier JC, Parola P, Hoang VT, Meddeb L, Mailhe $\mathrm{M}$, et al. Hydroxychloroquine and azithromycin as a treatment of COVID-19: results of an open-label non-randomized clinical trial. Int J Antimicrob Agents. 2020;20:105949. https://doi. org/10.1016/j.ijantimicag.2020.105949.

32. Cai Q, Yang M, Liu D, Chen J, Shu D, Xia J, et al. Experimental treatment with favipiravir for COVID-19: an open-label control study. Engineering. 2020. https://doi.org/10.1016/j. eng.2020.03.007.

33. Wang YM, Zhang DY, Du GH, Du R, Zhang J, et al. Remdesivir in adults with severe COVID-19: a randomised, double-blind, placebo-controlled, multicentre trial. Lancet. 2020. https://doi. org/10.1016/S0140-6736(20)31022-9.

34. Ji D, et al. Effect of COVID-19 on patients with compensated chronic liver diseases. Hepatol Int. 2020. (in press)

35. Ji D, Qin E, Xu J, Zhang D, Cheng G, Wang Y, Lau G. Implication of non-alcoholic fatty liver diseases (NAFLD) in patients with COVID-19: a preliminary analysis. J Hepatol. 2020. https://doi. org/10.1016/j.jhep.2020.03.044 (Epub ahead of print).

36. Sarin SK, Kumar M, Lau GK, Abbas Z, Chan HL, Chen CJ, et al. Asian-Pacific clinical practice guidelines on the management of hepatitis B: a 2015 update. Hepatol Int. 2016;10:1-98.

37. Wang JH, Chang KC, Kee KM, Chen PF, Yen YH, Tseng PL, et al. Hepatocellular carcinoma surveillance at 4- vs. 12-month intervals for patients with chronic viral hepatitis: a randomized study in community. Am J Gastroenterol. 2013;108:416-24.

38. Pangeli P, Bernardi M, Villanueva C, Francoz C, Mookerjee RP, Trebicka J, Krag A, et al. EASL Clinical Practice Guidelines for the management of patients with decompensated cirrhosis. J Hepatol. 2018;69(2):406-60.

39. Gu J, Han B, Wang J. COVID-19: gastrointestinal manifestations and potential fecal-oral transmission. Gastroenterology. 2020. https://doi.org/10.1053/j.gastro.2020.02.054 (Epub ahead of print).

40. To KK-W, Tsang OT-Y, Chik-Yan Yip C, Chan K-H, Wu T-C, Chan JMC, et al. Consistent detection of 2019 novel coronavirus in saliva. Clin Infect Dis. 2020. https://doi.org/10.1093/cid/ciaa1 49 (Epub ahead of print).

41. Soetikno R, Teoh AYB, Kaltenbach T, Lau JYW, Asokkumar $\mathrm{R}$, Cabral-Prodigalidad $\mathrm{P}$, et al. Considerations in performing endoscopy during the COVID-19 pandemic. Gastrointest Endosc. 2020. https://doi.org/10.1016/j.gie.2020.03.3758 (Epub ahead of print).

42. de Franchis R, Baveno VIF. Expanding consensus in portal hypertension: report of the Baveno VI consensus workshop: stratifying risk and individualizing care for portal hypertension. J Hepatol. 2015;63:743-52.

43. Wang W, Xu Y Gao R, Lu R, Han K, Wu G et al (2020) Detection of SARS-Cov2 in different types of clinical specimens. JAMA. https://jamanetwork.com/on. Accessed 19 Apr 20

44. Liu W, Tao ZW, Lei W, Ming-Li, Jing L, Shuang W, et al. Analysis of factors associated with disease outcomes in hospitalized patients with 2019 novel coronavirus disease. Chin Me J. 2020;133(9):1032-8.
45. Angelico R, Trapani S, Manzia TM, Lombardini L, Tisone G, Cardillo M. The COVID-19 outbreak in Italy: initial implications for organ transplantation programs. Am J Transplant. 2020. https ://doi.org/10.1111/ajt.15904 (Epub ahead of print).

46. Boyarsky BJ, Chiang TP, Werbel WA, Durand CM, Avery RK, Getsin SN, et al. Early impact of COVID-19 on transplant center practices and policies in the United States. Am J Transplant. 2020. https://doi.org/10.1111/ajt.15915(Epub ahead of print).

47. Zhou F, Yu T, Du R, Fan G, Liu Y, Liu Z, et al. Clinical course and risk factors for mortality of adult inpatients with COVID19 in Wuhan, China: a retrospective cohort study. Lancet. 2020;395(10229):1054-62. https://doi.org/10.1016/S0140 -6736(20)30566-3 (Epub 2020 Mar 11).

48. Garg S, Kim L, Whitaker M, O'Halloran A, Cummings C, Holstein R, et al. Hospitalization rates and characteristics of patients hospitalized with laboratory-confirmed coronavirus disease 2019-COVID-NET, 14 States, March 1-30, 2020. MMWR Morb Mortal Wkly Rep. 2020;69(15):458-64. https://doi.org/10.15585 /mmwr.mm6915e3.

49. Xu K, Chen Y, Yuan J, Yi P, Ding C, Wu W, et al. Factors associated with prolonged viral RNA shedding in patients with COVID-19. Clin Infect Dis. 2020. https://doi.org/10.1093/cid/ ciaa351(Epub ahead of print).

50. Zhong Z, Zhang Q, Xia H, Wang A, Liang W, Zhou W, et al. Clinical characteristics and immunosuppressants management of coronavirus disease 2019 in solid organ transplant recipients. Am J Transplant. 2020. https://doi.org/10.1111/ajt.15928 (Epub ahead of print).

51. Fernández-Ruiz M, Andrés A, Loinaz C, Delgado JF, LópezMedrano F, San Juan R, et al. COVID-19 in solid organ transplant recipients: a single-center case series from Spain. Am J Transplant. 2020. https://doi.org/10.1111/ajt.15929 (Epub ahead of print).

52. Bhoori S, Rossi RE, Citterio D, Mazzaferro V. COVID-19 in long-term liver transplant patients: preliminary experience from an Italian transplant centre in Lombardy. Lancet Gastroenterol Hepatol. 2020. https://doi.org/10.1016/S2468-1253(20),30116-3 (Epub ahead of print).

53. Mehta P, McAuley DF, Brown M, Sanchez E, Tattersall RS, Manson JJ, et al. COVID-19: consider cytokine storm syndromes and immunosuppression. Lancet. 2020;395(10229):1033-4. https:// doi.org/10.1016/S0140-6736(20)30628-0 (Epub 2020 Mar 16).

54. Liu H, He X, Wang Y, Zhou S, Zhang D, Zhu J, He Q, et al. Management of COVID-19 in patients after liver transplantation: Beijing working party for liver transplantation. Hepatol Int. 2020. https://doi.org/10.1007/s12072-020-10043-z (Epub ahead of print).

55. Boettler T, Newsome PN, Mondelli MU, Maticic M, Cordero E, Cornberg $\mathrm{M}$, et al. Care of patients with liver disease during the COVID-19 pandemic: EASL-ESCMID position paper. JHEP Rep. 2020;2(3):100113. https://doi.org/10.1016/j.jhepr.2020.100113 (Epub ahead of print).

56. Fix OK, Hameed B, Fontana RJ, Kwok RM, McGuire BM, Mulligan DC, Pratt DS, Russo MW, Schilsky ML, Verna EC, Loomba R, Cohen DE, Bezerra JA, Reddy KR, Chung RT. AASLD clinical insights for hepatology and liver transplant providers during the covid-19 pandemic. Hepatology. 2020. https://doi.org/10.1002/ hep.31281. Accessed 12 May 2020.

57. Transplant Society of Australia and New Zealand: COVID-19National Transplantation and Donation Rapid Response Taskforce. https://www.tsanz.com.au/Website\%20Update\%20-\%20 COVID-19\%20as\%20at\%2015\%20April\%202020\%20FINAL.pdf. Accessed 25 Apr 2020.

58. Lleo A, Invernizzi P, Lohse AW, Aghemo A, Carbone M. Highlights for management of patients with Autoimmune Liver 
Disease during COVID-19 pandemia. J Hepatol. 2020. https:// doi.org/10.1016/j.jhep.2020.04.002 (Epub ahead of print).

59. Meng H, Xiong R, He R, Lin W, Hao B, Zhang L, et al. CT imaging and clinical course of asymptomatic cases with COVID-19 pneumonia at admission in Wuhan, China. J Infect. 2020. https:// doi.org/10.1016/j.jinf.2020.04.004 (Epub ahead of print).

60. Serper M, Cubell AW, Deleener ME, Casher TK, Rosenberg DJ, Whitebloom D, et al. Telemedicine in liver disease and beyond: can the COVID-19 crisis lead to action? Hepatology. 2020. https ://doi.org/10.1002/hep.31276 (Epub ahead of print).

61. Omata M, Cheng AL, Kokudo N, Kudo M, Lee JM, Jia J, et al. Asia-Pacific clinical practice guidelines on the management of hepatocellular carcinoma: a 2017 update. Hepatol Int. 2017;11:317-70.

62. Raturi M, Kusum A. The active role of a blood center in outpacing the transfusion transmission of COVID-19. Transfus Clin Biol. 2020;27(2):96-7.

63. Shander A, Goobie SM, Warner MA, Aapro M, Bisbe E, PerezCalatayud AA, et al. The essential role of patient blood management in a pandemic: a call for action. Anesth Analg. 2020. https ://doi.org/10.1213/ANE.0000000000004844 (Epub ahead of print).

64. Hirotsu Y, Maejima M, Nakajima M, Mochizuki H, Omata M. Environmental cleaning is effective for the eradication of severe acute respiratory syndrome coronavirus 2 (SARS-CoV-2) in contaminated hospital rooms: a patient from the Diamond Princess cruise ship. Infect Control Hosp Epidemiol. 2020. https://doi. org/10.1017/ice.2020.144 (Epub ahead of print).

65. The Japan Society for Transplantation (in Japanese): https://squar e.umin.ac.jp/jst-covid-19/images/guidance2.pdf. Accessed $22 \mathrm{Apr}$ 2020.

66. Kamboj M, Sepkowitz KA. Nosocomial infections in patients with cancer. Lancet Oncol. 2009;10:589-97.

67. Liang W, Guan W, Chen R, Wang W, Li J, Xu K, et al. Cancer patients in SARS-CoV-2 infection: a nationwide analysis in China. Lancet Oncol. 2020;21:335-7. https://doi.org/10.1016/S1470 -2045(20)30096-6.

68. Clay JM, Parker MO. Alcohol use and misuse during the COVID19 pandemic: a potential public health crisis? Lancet Public
Health. 2020. https://doi.org/10.1016/S2468-2667(20),30088-8 (Epub ahead of print).

69. Wu Z, McGoogan JM. Characteristics of and important lessons from the coronavirus disease 2019 (COVID-19) outbreak in China: summary of a report of 72,314 cases From the Chinese Center for Disease Control and Prevention. JAMA. 2020. https:// doi.org/10.1001/jama.2020.2648 (Epub ahead of print).

70. Lippi G, de Oliveira MHS, Henry BM. Chronic liver disease is not associated with severity or mortality in Coronavirus disease 2019 (COVID-19): a pooled analysis. Eur J Gastroenterol Hepatol. 2020. https://doi.org/10.1097/MEG.0000000000001742 (Epub ahead of print).

71. Chen X, Jiang Q, Ma Z, Ling J, Hu W, Cao Q, et al. Clinical characteristics of hospitalized patients with SARS-CoV-2 and hepatitis B virus co-infection. medRxiv. 2020. https://doi. org/10.1101/2020.03.23.20040733.

72. Guan WJ, Ni ZY, Hu Y, Liang WH, Ou CQ, He JX, et al. Clinical characteristics of coronavirus disease 2019 in China. N Engl J Med. 2020. https://doi.org/10.1056/NEJMoa2002032 (Epub ahead of print).

73. Ali S, Egunsola O, Babar ZUD, Hasan SS. Clinical trials in Asia: a World Health Organization database study. Perspect Clin Res. 2019;10(3):121-4. https://doi.org/10.4103/picr.PICR_109_18.

74. Boettler T, Newsome PN, Mondelli MU, Maticic M, Cordero E, Cornberg M, Berg T. Care of patients with liver disease during the COVID-19 pandemic: EASL-ESCMID position paper. JHEP Rep. 2020;2(3):100113.

75. COVID-19-Related Guidance Documents for Industry, FDA Staff, and Other Stakeholders. https://www.fda.gov/emergency-prepa redness-and-response/coronavirus-disease-2019-covid-19/covid -19-related-guidance-documents-industry-fda-staff-and-other -stakeholders. Accessed 25 Apr 2020.

Publisher's Note Springer Nature remains neutral with regard to jurisdictional claims in published maps and institutional affiliations. 